\title{
Eco-innovación, pymes e incentivos fiscales
}

\author{
Ekoinnowacje, MŚP i zachęty podatkowe
}

\author{
Elizabeth Gil García \\ Universidad de Alicante
}

\section{Introducción}

La pandemia ha puesto de manifiesto la necesidad de crear un entorno empresarial más justo y sostenible, teniendo en cuenta que las pequeñas empresas suelen encontrar mayores dificultades para iniciar su actividad y expandirse en un mercado único ${ }^{1}$. Como es sabido, uno de los principios clave en los que se apoya la recuperación es la transición ecológica² ${ }^{2}$ lo que implica la adopción de medidas que promuevan una economía más circular que aumente la resiliencia de la UE mediante el desarrollo de "modelos empresariales innovadores por tecnologías digitales para mejorar el uso eficiente de los recursos y las materias primas secundarias"3. Estaría esto ligado a la idea de eco-innovación (considerada como 'doble externalidad positiva' $)^{4}$, la cual consiste en desarrollar y aplicar un modelo empresarial basado en la sostenibilidad de todas las actividades de la empresa a partir del análisis del ciclo de vida, y en cooperación con diversos socios en la cadena de generación de valor ${ }^{5}$.

La innovación y el progreso tecnológico son, por tanto, claves para determinar soluciones a medio y largo plazo para los retos económicos y ambientales. En este sentido, las subvenciones, los beneficios fiscales, las ayudas públicas en forma de préstamos participativos o los anticipos reembolsables, inter alia, constituyen relevantes instituciones de fomento a la innovación. En España, tradicionalmente, se han venido dedicando recursos directos para las actividades de $\mathrm{I}+\mathrm{D}+\mathrm{i}^{6}$ realizadas por el sector público-principalmente, universidades y Organismos Públicos de In-

${ }^{1}$ COM (2020) 575 final, Estrategia anual de crecimiento sostenible 2021, p. 4.

${ }^{2}$ Sobre el Plan de Recuperación de la Unión Europea, puede verse: https://ec.europa.eu/info/strategy/ recovery-plan-europe_es [acceso 13 marzo 2021].

${ }^{3}$ COM (2020) 575 final, p. 7.

${ }^{4}$ Esta consideración suele basarse en el hecho de que la $\mathrm{I}+\mathrm{D}+\mathrm{i}$ puede proporcionar conocimiento y oportunidades de mejora ambiental y, al mismo tiempo, la necesidad de alcanzar los objetivos ambientales puede generar más I+D+i.

${ }^{5}$ ONU Medio Ambiente (con la Comisión Europea), Integración de la eco-innovación en las Políticas de consumo y producción sostenibles, 2017, p. 16.

${ }^{6}$ Por sus letras: Investigación, desarrollo e innovación. 
vestigación (OPIs). Para la empresa, especialmente para las pequeñas y medianas empresas (pymes), si bien la subvención suele presentarse como una buena forma de iniciarse en actividades de $\mathrm{I}+\mathrm{D}+\mathrm{i}$, suele (al mismo tiempo) presentarse como un mecanismo incierto y de un alto coste administrativo ${ }^{7}$. Como decíamos, el Estado puede estimular la innovación también a través de las normas tributarias, fomentando que otros sujetos lo hagan por la posibilidad de obtener beneficios fiscales. De esta forma, y si bien deviene esencial el mantenimiento e incremento de los recursos destinados al sector público, el fomento ha de extenderse también a la $\mathrm{I}+\mathrm{D}+\mathrm{i}$ realizada desde el sector empresarial.

Por otra parte, cabe destacar que el fomento del consumo y la inversión son clave para la recuperación de la crisis sanitaria originada por la COVID-19, por lo que la introducción de medidas fiscales de estímulo puede contribuir a ello ${ }^{8}$. En este sentido, la OCDE ha señalado, como una opción de política fiscal para la recuperación, conceder un tratamiento fiscal preferente para aquellas inversiones, como la $\mathrm{I}+\mathrm{D}+\mathrm{i}$ o el medio ambiente (environment-friendly investments), que se caracterizan por sus efectos positivos indirectos. Destaca también la OCDE la necesidad de fomentar aquellas inversiones que refuercen a las economías no sólo para superar la actual crisis sanitaria (y subsiguiente crisis socio-económica) sino para salir reforzados de la misma de cara a hacer frente a otras posibles crisis ${ }^{9}$. Así, los incentivos fiscales no solamente se usarían como instrumento de estímulo a la inversión empresarial -aliviando los efectos de la pandemia- sino también para promover determinadas inversiones que coadyuven a aumentar la resiliencia del sistema, como la $\mathrm{I}+\mathrm{D}+\mathrm{i}$, la salud o las tecnologías bajas en carbono, entre otras.

En relación con esto último, ha de tenerse en cuenta que la madurez de las denominadas "tecnologías verdes" (o "green technologies") no siempre se encuentra en un estado lo suficientemente avanzado para alcanzar los retos ambientales, por lo que podría ser preferible acudir (primero) a incentivos fiscales a la $\mathrm{I}+\mathrm{D}+\mathrm{i}$ que permitan asegurar el óptimo desarrollo de esas tecnologías ${ }^{10}$. En efecto, el coste de implementar la eco-innovación implica realizar una inversión inicial significativa que puede resultar inhibidor para numerosas empresas, especialmente para las pymes por la menor disponibilidad de recursos financieros ${ }^{11}$.

${ }^{7}$ F. Alonso Murillo, Fiscalidad de la I+D+i. Tratamiento de los gastos en el Impuesto sobre Sociedades, Netbiblo, 2010, p. 14

${ }^{8}$ OECD (2020), Tax and Fiscal Policy in Response to the Coronavirus Crisis: Strengthening Confidence and Resilience, OECD Publishing, p. 10.

${ }^{9}$ Ibidem, p. 34.

${ }^{10}$ En términos similares, Milne y Villar consideran que los incentivos a la I+D se pueden establecer para el desarrollo de determinadas tecnologías de modo que se acelere la madurez tecnológica de las fuentes de producción que se buscan estimular. De lo contrario, la falta de madurez tecnológica podría no garantizar una rentabilidad suficiente en la larga vida de una instalación de producción eléctrica (J.E. Milne, M. Villar, Renewable Electricity and Tax Expenditures: Lessons from Two Countries, „Intertax” 2020, vol. 48, n 4, p. 385).

${ }^{11}$ ONU Medio Ambiente (con la Comisión Europea), Integración..., p. 24. 
En consecuencia, este trabajo se centra en el diseño y configuración de incentivos fiscales a la $\mathrm{I}+\mathrm{D}+\mathrm{i}$ que pueden favorecer la madurez tecnológica para hacer frente a los retos ambientales. Pues, en esencia, el apoyo a la I+D contribuye al desarrollo de alternativas innovadoras. Dado que las formas que puede adoptar un incentivo fiscal son variadas y obedecen a cuestiones de política fiscal de cada uno de los Estados $^{12}$, consideramos que, en la Unión Europea, donde el tejido empresarial está compuesto mayoritariamente por pymes, debe tomarse en consideración (entre otras variables) el tamaño de las empresas al adoptar un incentivo. Además, en cuanto a las ventajas de la eco-innovación, se considera que su implantación en las pymes puede contribuir a "atenuar las limitaciones de recursos y la degradación del medio ambiente, a mejorar el bienestar social y la participación de comunidades locales, la creación de empleo, y la capacidad para atraer recursos financieros" ${ }^{13}$.

Por tanto, el trabajo se organiza en cuatro apartados. El segundo de ellos resalta aquellos aspectos más relevantes que deben tenerse en cuenta al configurar un incentivo fiscal que pretenda promover la $\mathrm{I}+\mathrm{D}+\mathrm{i}$ de las pymes en el camino hacia una transición verde, siendo clave la presencia de personal investigador cualificado y la difusión de soluciones eco-innovadoras. Seguidamente, se aborda la cuestión del control del incentivo a fin de poder verificar que con el mismo se están alcanzando los objetivos previstos, siendo en este sentido relevante el establecimiento de un riguroso sistema de certificaciones a la I+D+i o también de la denominada 'contabilidad verde.' Finalmente, el capítulo termina con las principales ideas y conclusiones.

\section{La configuración del incentivo: estímulo a la contratación de personal investigador y a la transferencia de conocimiento}

Ha de apuntarse, en primer lugar, que el interés de un país por incrementar la inversión en $\mathrm{I}+\mathrm{D}+\mathrm{i}$ se basa en su consideración como clave para el crecimiento, productividad y bienestar social. Precisamente, esta consideración es lo que sirve de base para justificar la intervención estatal, esto es, que la I+D+i sea una actividad merecedora de financiación pública por encontrarse amparada en valores constitucionales o políticas de interés público ${ }^{14}$. Por tanto, el incentivo fiscal debe ir dirigido a la promoción del proceso de investigación, transferencia e innovación tecnológica para que su uso sea considerado legítimo. En otras palabras, el incentivo

${ }^{12}$ B. Corchuelo Martínez-Azúa, Incentivos fiscales a la I+D en la OCDE: estudio comparativo, „Cuadernos económicos de ICE” 2007, nº 73, p. 198.

${ }^{13}$ ONU Medio Ambiente (con la Comisión Europea), Integración..., p. 17.

${ }^{14}$ Por ejemplo, en España, el art. 44 de la Constitución contiene obligaciones para los poderes públicos en cuanto a la promoción de la ciencia y la investigación. De modo similar, la Constitución italiana establece la promoción de la investigación científica y técnica; y, la Constitución portuguesa señala que el Estado incentivará y apoyará la investigación científica y la innovación tecnológica. 
ha de configurarse de modo que efectivamente se cumpla el objetivo de fomento que se pretende conseguir.

Cuando se habla de $\mathrm{I}+\mathrm{D}+\mathrm{i}$ han de distinguirse dos momentos. Por un lado, la $\mathrm{I}+\mathrm{D}+\mathrm{i}$ como actividad $\mathrm{y}$, por otro, la $\mathrm{I}+\mathrm{D}+\mathrm{i}$ como resultado. Este trabajo se centra en la introducción de incentivos fiscales a la actividad, esto es, incentivos que fomentan o estimulan la inversión empresarial en $\mathrm{I}+\mathrm{D}+\mathrm{i}$. Centrándonos en el incentivo como deducción en cuota (o tax credit), que es la forma más extendida entre los países de la $\mathrm{UE}^{15}$, ésta puede establecerse sobre el volumen o sobre el incremento.

En el primer caso, la deducción se basa en el volumen de gastos en I+D+i efectuados en un año fiscal ${ }^{16}$, aplicando a tales efectos un porcentaje determinado sobre el total de gastos elegibles ${ }^{17}$. Ahora bien, este tipo de incentivo no requiere que nueva $\mathrm{I}+\mathrm{D}+\mathrm{i}$ sea llevada a cabo e incluso puede seguir siendo usado, aunque el nivel de gastos de $\mathrm{I}+\mathrm{D}+\mathrm{i}$ disminuya (con la consiguiente disminución del incentivo) ${ }^{18}$. De esta forma, se estaría concediendo un incentivo respecto de actividades que podrían haber sido igualmente llevadas a cabo sin la presencia del incentivo ${ }^{19}$.

Por su parte, un incentivo sobre el incremento solamente se aplica cuando el gasto en $\mathrm{I}+\mathrm{D}+\mathrm{i}$ crece, limitando así la financiación a actividades de $\mathrm{I}+\mathrm{D}+\mathrm{i}$ adicionales. Por lo general, para poder acceder al incentivo, el gasto en $\mathrm{I}+\mathrm{D}+\mathrm{i}$ del año en cuestión debe superar al del año anterior o la media de los últimos años ${ }^{20}$. Este tipo de incentivos sobre el incremento puede suscitar estrategias acerca de cuándo y por quién serán realizadas las actividades de $\mathrm{I}+\mathrm{D}+\mathrm{i}^{21}$. Por ejemplo, aquellas entidades que de manera continuada vienen invirtiendo una determinada cuantía en $\mathrm{I}+\mathrm{D}+\mathrm{i}$ no podrían acceder al incentivo (al no haber un incremento con respecto a años anteriores), por lo que podrían cambiar su estrategia y optar por reducir sus actividades de $\mathrm{I}+\mathrm{D}+\mathrm{i}$ para así poder beneficiarse de incentivos en el futuro ${ }^{22}$. En el caso de las pymes (o las start-ups), al ser su capacidad para iniciarse y desarrollar I+D+i más limitada, conseguir aumentar gradualmente su gasto en $\mathrm{I}+\mathrm{D}+\mathrm{i}$ resultaría aún más complicado.

${ }^{15}$ Comisión Europea, A Study on R\&D Tax Incentives. Final report, Working Paper no 52, 2014, p. 53.

${ }^{16}$ C. Brokelind, Å. Hansson, TAX Incentives, Tax Expenditures Theories in RßD: The Case of Sweden", „World Tax Journal” 2014, vol. 6, n 2, p. 177.

${ }^{17}$ C. Rivas Sánchez, Los incentivos fiscales a la innovación en España y en el ámbito comparado, Crónica Tributaria, 2008, nº 127, p. 140.

${ }^{18}$ C. Brokelind, Å. Hansson, op. cit., p. 177.

${ }^{19}$ M. Abdellatif, Looking for Efficient Tax Incentives to Stimulate Research and Development and Economic Growth, „New Zealand Journal of Taxation and Policy” 2009, vol. 15, n 2, pp. 141-142; P. Arginelli, Innovation through ReD Tax Incentives: Some Ideas for a Fair and Transparent Tax Policy, „World Tax Journal” 2015, vol. 7, no 1, p. 27; A. Bal, Competition for Research \& Development Tax Incentives in the European Union How and Optimal Research \& Development System Should Be Designed, „Bulletin for International Taxation” 2012, vol. 66, n 10, p. 575; C. Brokelind, Å. Hansson, op. cit., p. 177; C. Rivas Sánchez, op. cit., pp. 140-141.

${ }^{20}$ C. Brokelind, Å. Hansson, op. cit., p. 178.

${ }^{21}$ Ibidem.

${ }^{22}$ A. Bal, Tax Incentives: III-Advised Tax Policy or Growth Catalaysts?, „European Taxation” 2014, vol. $54, n^{\circ} 2 / 3$, p. 67. 
Por ende, mientras que un incentivo sobre el volumen se caracteriza por 'premiar' una $\mathrm{I}+\mathrm{D}+\mathrm{i}$ ya realizada que no implica necesariamente un avance científico o tecnológico, un incentivo sobre el incremento 'premia' a aquella empresa que eleva su inversión en $\mathrm{I}+\mathrm{D}+\mathrm{i}$. Lógicamente, será indiferente uno u otro tipo de incentivo para aquella empresa que no había invertido anteriormente en $\mathrm{I}+\mathrm{D}+\mathrm{i}$. Pues, en su primer año realizando gasto en $\mathrm{I}+\mathrm{D}+\mathrm{i}$ podría resultar beneficiaria en ambos tipos de regímenes ${ }^{23}$.

Una posible opción para tratar de aunar las ventajas de ambas modalidades y tratar de evitar las deficiencias de cada una de ellas, sería establecer un sistema mixto o combinado. Con ello, se podría beneficiar al sujeto que cuenta con una trayectoria regular en la realización de actividades de investigación científica e innovación, como beneficiar significativamente a aquel sujeto que, de manera progresiva, aumenta su esfuerzo inversor en $\mathrm{I}+\mathrm{D}+\mathrm{i}$. Eso es precisamente lo que ocurre con la deducción española del art. 35 de la Ley del Impuesto sobre Sociedades (LIS), que establece un $25 \%$ para los gastos elegibles en I+D efectuados en el período impositivo en cuestión y para los casos en que haya un incremento del gasto en I+D con respecto a los efectuados en los dos años anteriores, se establece un $42 \%$ adicional sobre el exceso o incremento. Ello permite mantener y además premiar a aquellas entidades que realizan un esfuerzo adicional por incrementar la inversión en $\mathrm{I}+\mathrm{D}+\mathrm{i}$ y, por tanto, ser empresas más innovadoras, al poder implementar lo investigado.

Más allá de la forma que adopte el incentivo, otro de los aspectos destacables sobre el diseño se refiere a la base del incentivo, esto es, los gastos elegibles que aquél va a cubrir. En este sentido, deben considerarse especialmente los gastos del personal investigador, pues la contratación de personal altamente cualificado es costosa y, además, junto al inmovilizado, es pieza esencial en todo proceso de $\mathrm{I}+\mathrm{D}+\mathrm{i}$. Cabe destacar que, precisamente, el personal de I+D y los investigadores son uno de los indicadores de eco-innovación incluidos en el Plan de Acción sobre Eco-innovación de la UE ${ }^{24}$. En España, la deducción del art. 35 LIS establece una deducción adicional del $17 \%$ respecto del importe de los gastos de personal. De este modo, no solamente se incentiva desde el sistema fiscal la contratación de personal investigador por la posibilidad de deducirse el coste de su contratación, sino que ello además puede coadyuvar a que las pymes puedan llevar a cabo por sí mismas un proceso de $\mathrm{I}+\mathrm{D}+\mathrm{i}$ o incluso llegar a tener su propio departamento de $\mathrm{I}+\mathrm{D}+\mathrm{i}$, al requerir el art. 35 LIS que el personal investigador esté exclusivamente adscrito a actividades de $\mathrm{I}+\mathrm{D}$.

Además, una ventaja adicional para las pymes es la compatibilidad de esta deducción fiscal con la bonificación en la cotización a la Seguridad Social respecto del personal investigador. A tales efectos, es preciso que la entidad sea reconocida

${ }^{23}$ E. Gil García, Los incentivos fiscales a la $I+D+i$, Tirant lo Blanch, 2017, p. 160.

${ }^{24}$ Los indicadores a la eco-innovación, así como los resultados por Estados miembros en eco-innovación pueden consultarse en: https://ec.europa.eu/environment/ecoap/indicators/index_es [acceso 13 marzo 2021]. 
como pyme innovadora. Ello viene definido por el Real Decreto 475/2014, de 13 de junio, a partir de la concurrencia de determinadas circunstancias. Mientras que la primera circunstancia se refiere a la obtención de financiación a través de convocatorias públicas en $\mathrm{I}+\mathrm{D}+\mathrm{i}$ en los últimos tres años (como, por ejemplo, el Programa Horizonte 2020), las otras dos circunstancias tienen que ver con la obtención de patentes o determinadas certificaciones. Así pues, la pyme tiene la consideración de intensiva en $\mathrm{I}+\mathrm{D}+\mathrm{i}$ cuando dispone de una patente propia en explotación en un período no superior a cinco años o bien porque en los últimos tres años ha recibido un informe motivado vinculante positivo a efectos de la deducción del art. 35 LIS. Igualmente, también tiene la consideración de pyme innovadora aquella empresa que obtiene determinadas certificaciones oficiales, como el de joven empresa innovadora (JEI) o el de pequeña o microempresa innovadora.

El cumplimiento de una de esas circunstancias permite a la pyme reconocida como intensiva en $\mathrm{I}+\mathrm{D}+\mathrm{i}$ acceder al Registro de Pymes Innovadoras, lo que - como decíamos - implica la compatibilidad respecto del mismo personal investigador de la bonificación del $40 \%$ en las aportaciones empresariales a la Seguridad Social con la deducción del art. 35 LIS.

En relación con lo anterior, y teniendo en cuenta que las pymes encuentran mayores dificultades de financiación para sus proyectos $\mathrm{de} I+\mathrm{D}+\mathrm{i}$, es recomendable que el incentivo tenga en cuenta las particularidades de este tipo de empresas para que puedan acceder a los mismos. Por ejemplo, la Comisión Europea, en su Informe sobre España de febrero de 2020, destacaba que las pequeñas empresas tienden a responder peor que las grandes empresas a la deducción del art. 35 LIS, la cual, a pesar de su generosidad, se caracteriza por la escasez de resultados ${ }^{25}$. También la Asociación Española para el Fomento de la Financiación de la I+D+i (AFIDI) señala que el menor tamaño de las empresas españolas (en comparación con otros países de nuestro entorno) las hace más vulnerables y con mayores dificultades para ser innovadoras ${ }^{26}$.

Así, y en aras de un gasto público justo, la eficiencia en la utilización del gasto público para favorecer actividades de $\mathrm{I}+\mathrm{D}+\mathrm{i}$ va a requerir limitar la intervención estatal a aquellos escenarios en que su uso represente un valor añadido. Consideramos que, precisamente, en estos escenarios caracterizados por la falta o escasez de medios para realizar una actividad de $\mathrm{I}+\mathrm{D}+\mathrm{i}$, la necesidad de la ayuda estaría justificada ${ }^{27}$, pues, quizás en otro caso, la misma no se llevaría a cabo ${ }^{28}$. Lo ideal es que

${ }^{25}$ Comisión Europea (2020), Informe sobre España que acompaña a la Comunicación sobre el Semestre Europeo 2020, $\operatorname{COM(2020)} 150$ final, p. 43.

${ }^{26}$ AFIDI (2020), Dura crítica de Bruselas a los incentivos fiscales a la I+D en España: son complejos e ineficaces [disponible en el sitio web de AFIDI: http://www.afidi.es/2020/04/06/dura-critica-de-bruselas-a-los-incentivos-fiscales-a-la-id-en-espana-son-complejos-e-ineficaces/ [acceso 13 marzo 2021].

${ }^{27}$ De hecho, el Reglamento General de Exención por Categorías (GBER) excluye las ayudas a la innovación en favor de las pymes de la prohibición de ayudas de Estado del art. 107 TFUE, siempre y cuando cumplan las condiciones establecidas.

${ }^{28}$ E. Gil García, Los incentivos..., p. 193. 
aquellos proyectos, cuyo rendimiento social supera el coste total, sean financiados para que puedan llevarse a cabo, pues de no ser así se estarían financiado proyectos que podrían haberse realizado sin ayuda financiera y que supondrían una perdida ${ }^{29}$. Como es lógico, la contrapartida de beneficiar a este tipo de empresas puede ser la falta de certeza acerca de su viabilidad económica a medio o largo plazo.

Por otro lado, son diversos los estudios que consideran que los incentivos fiscales dirigidos a las pymes tienden a ser más efectivos y suponen menos pérdidas que los establecidos para grandes empresas ${ }^{30}$. Por ejemplo, el régimen francés de la joven empresa innovadora (Jeune Entreprise Innovante) está considerado como buena práctica fiscal por un estudio de la Comisión Europea ${ }^{31}$. En concreto, con este régimen se buscaba favorecer la creación de pymes que efectúan trabajos de investigación, concediéndoles ventajas fiscales y bonificaciones en las cotizaciones a la Seguridad Social ${ }^{32}$. Señala además la Comisión en ese estudio de 2014 que un clima favorable para los emprendedores puede contribuir a la innovación y a la flexibilidad económica de un país, siendo incluso mejor práctica estimular a las jóvenes empresas (como las start-ups) que a las pymes ${ }^{33}$.

Ahora bien, el hecho de que el incentivo favorezca en mayor medida a determinadas entidades (undertakings), como las pymes, podría entrar en colisión con las normas sobre ayudas de Estado, en base al criterio de la selectividad. No obstante, la compatibilidad del incentivo pasa porque esté dentro de un área de justificación. Lo que, en nuestra opinión, implica atender al efecto incentivador que produce, al objetivo de interés público que persigue y a su consecución conforme a criterios de economía, eficiencia y proporcionalidad ${ }^{34}$.

Otro aspecto relevante que ha de considerarse es el fomento de la colaboración en $\mathrm{I}+\mathrm{D}+\mathrm{i}$, ya sea entre empresas o bien con el sector público. Esto puede ayudar a las pymes a ser innovadoras. En el primer supuesto, a la hora de configurar el incentivo ha de evitarse que el mismo promueva la mera adquisición de intangibles, por lo que deberían establecerse condiciones de desarrollo que permitan así que haya una actividad sustantiva. Nos merece un juicio más favorable que el incentivo busque promover la colaboración público-privada. De este modo, las empresas pueden desarrollar e implementar en sus procesos productivos las patentes generadas por universidades o centros públicos de investigación, haciendo así que sean innovadoras. Ello permite además la transferencia de conocimiento, evitando que

${ }^{29}$ C. Brokelind, Å. Hansson, op. cit., p. 176.

${ }^{30}$ B. Lokshin, P. Mohnen, Measuring the Effectiveness of R\&D tax credits in the Netherlands, CIRANO-Scientific Publications, 2007, p. 22; R. Baghana, P. Mohnen, Effectiveness of R\&D tax incentives in small and large enterprises in Quebec, „Small Business Economics” 2009, vol. 33, nº 1, pp. 91-107.

${ }^{31}$ Comisión Europea, $A$ Study on R\&D..., p. 7.

${ }_{32}$ Artículo 13 de la Loi de Finances pour 2004 n 2003-1311 du 30 décembre 2003.

${ }^{33}$ Comisión Europea, A Study on R\&D..., p. 7.

${ }^{34} \mathrm{E}$. Gil García, A review of the pre and post COVID-19 State aid rules in the área of R\&D\&I, „Crónica Tributaria" 2020, nº 175, pp. 106-110. 
las investigaciones realizadas en tales centros "se queden en un cajón" y que, por tanto, "traspasen los muros de los laboratorios". De hecho, AFIDI señala que, entre las variables que afectan a la inversión en $\mathrm{I}+\mathrm{D}+\mathrm{i}$ en España, se encuentra la falta de transferencia de conocimiento de la I+D a la innovación empresarial ${ }^{35}$. En el mismo sentido se pronuncia la ONU Medio Ambiente en su Informe de 2017 sobre la eco-innovación, al señalar entre las barreras a la misma, las deficiencias de los sistemas para la innovación; siendo precisa la interacción entre empresas, universidades e instituciones de investigación técnica ${ }^{36}$.

De esta forma, las empresas que no tienen su propio departamento de I+$\mathrm{D}+\mathrm{i}$ o no tienen la capacidad para llevar a cabo por ellas mismas un proceso de I $+\mathrm{D}+\mathrm{i}$ (como suele ser el caso de las pymes), se sirven de los laboratorios, instalaciones y personal de las universidades u OPIs para llevar a cabo el mismo ${ }^{37}$. Así, los resultados de la investigación científica son transferidos y permiten a las empresas innovar. Es decir, la transformación de una idea o descubrimiento científico en un nuevo o mejorado producto o proceso.

Se trata, en definitiva, de fomentar la creación de puentes entre el sector público de investigación y el sector empresarial, estableciendo, por ejemplo, un porcentaje de deducción mayor en esos casos (lo que podríamos llamar el binomio 'empresa-investigación pública') ${ }^{38}$. Cuestión que se contemplaba en nuestra normativa sobre sociedades hasta el año 2008, cuando, como consecuencia de la vulneración de libertades fundamentales, el gobierno optó por eliminar esa deducción adicional, en lugar de extenderla en casos de subcontratación de I+D a universidades o centros de investigación situados no sólo en España sino en cualquier otro Estado miembro de la UE/EEE. Así, el art. 35 LIS establecía una deducción adicional del 20\% para los gastos correspondientes a proyectos de $\mathrm{I}+\mathrm{D}$ contratados con universidades, OPIs o centros de innovación y tecnología, reconocidos y registrados conforme a la normativa española. Si bien es cierto que no se exigía que el centro de investigación estuviese en España para beneficiarse de la deducción adicional, era necesario que la actividad se realizase en España para poder obtener el citado reconocimiento. Lo que en la práctica implicaba que las empresas españolas encomendaran tareas de

${ }^{35}$ AFIDI (2020), op. cit.

${ }^{36}$ ONU Medio Ambiente (con la Comisión Europea), Integración..., p. 24.

${ }^{37}$ Como se ha dicho, el GBER excluye las ayudas a la innovación en favor de las pymes de la prohibición de ayudas de Estado cuando se cumplen determinadas circunstancias. Se establece que esas ayudas cubren, entre otros, los costes de envío en comisión de servicio de personal investigador procedente de un organismo de investigación, universidades u organismos de transferencia de tecnología (o también de una gran empresa) para que trabaje en actividades de $\mathrm{I}+\mathrm{D}+\mathrm{i}$ en una función recientemente creada en la entidad beneficiaria.

${ }^{38}$ Como señala Pérez Bernabeu, la colaboración público-privada en $\mathrm{I}+\mathrm{D}+\mathrm{i}$ se entiende como la participación en proyectos conjuntos de innovación entre sujetos del sector público y agentes del sector privado, más allá de la mera contratación de trabajos (B. Pérez Bernabeu, La $I+D+i$ colaborativa a la luz de la normativa sobre ayudas de Estado (Especial referencia a las Spin-off universitarias), „Crónica Tributaria” 2015, no 156, p. 176). 
$\mathrm{I}+\mathrm{D}$ a universidades $\mathrm{u}$ organismos de investigación situados dentro del territorio español. De este modo, como señalaba el TJUE en el asunto Comisión vs. España (C-248/06, 13 marzo 2008) se estaba restringiendo la libertad de servicios al disuadir a las empresas españolas a que contrataran $\mathrm{I}+\mathrm{D}$ con centros situados en otros Estados miembros.

Así pues, como hemos tenido ocasión de apuntar en otras ocasiones, el fomento de la ciencia e investigación nacional no debe implicar la restricción de las libertades fundamentales. Pues, de hecho, el art. 179 TFUE aboga por la creación de un espacio europeo de investigación sin fronteras donde puedan crearse intercambios y flujos de conocimiento, y donde se fomente la transferencia de conocimiento y la difusión de la excelente investigación que se lleva a cabo en Europa ${ }^{39}$.

Finalmente, y como se adelantaba ya en la introducción de este capítulo, los incentivos fiscales pueden estimular inversiones en tecnologías verdes, lo que requiere primero de un proceso de $\mathrm{I}+\mathrm{D}+\mathrm{i}$ que permita el desarrollo óptimo de las mismas. En consecuencia, podrían establecerse deducciones especiales o un porcentaje de deducción adicional respecto de determinadas actividades o sectores (como la energía). Puede destacarse, en este sentido, la deducción adicional que establece el Código belga de los Impuestos sobre la Renta de 1992 (Code des Impôts sur les Revenus, CIR 92) en relación con la investigación y desarrollo de productos nuevos y tecnologías avanzadas que no tengan efectos negativos sobre el medio ambiente o que contribuyan a minimizar los efectos sobre el mismo (art. 69 pf. 1. 2b) CIR 921). También en España se ha establecido que la deducción por actividades de innovación tecnológica del art. 35.2 LIS se incremente en 38 puntos para los períodos impositivos 2020 y 2021 respecto de las actividades que supongan un avance tecnológico en la obtención de nuevos procesos de producción en la cadena de valor de la industria de la automoción o mejoras sustanciales de los ya existentes ${ }^{40}$.

Estos ejemplos muestran como el incentivo fiscal va dirigido a determinadas actividades o tecnologías. En concreto, el apoyo público a la eco-innovación suele centrarse en sectores como el agua, la energía y el transporte ${ }^{41}$. Ello podría entrar en colisión con el art. 107 TFUE al estar la ayuda pública, en forma de incentivo fiscal, orientada a favorecer determinados sectores ${ }^{42}$. Ahora bien, ha de recordarse, por un lado, que el art. 107.3 TFUE establece la compatibilidad (previo análisis de la Comisión) de las ayudas destinadas a facilitar el desarrollo de determinadas

${ }^{39}$ E. Gil García, Los incentivos..., p. 208.

${ }^{40}$ Esto además iría en línea con el documento del Fondo Monetario Internacional (FMI) que recomienda, para la superación de la crisis originada por la COVID-19, la introducción de incentivos a la inversión que sean temporales (normalmente, de 1 a 3 años), acelerando así los planes empresariales de inversión (FMI (2020), Temporary Investment Incentives, Fiscal Affairs - Special Series on COVID-19).

${ }^{41}$ ONU Medio Ambiente (con la Comisión Europea), Integración..., p. 28.

${ }^{42}$ Esto es lo que la Comisión identifica como selectividad sectorial, la cual se refiere a aquellas medidas que buscar estimular las actividades de las empresas pertenecientes a un sector de la economía. 
actividades y, por otro, como decíamos anteriormente, si la ayuda se encontrase dentro de un área de justificación, a pesar de la selectividad, resultaría compatible con el mercado único.

\section{El control de los incentivos fiscales: las certificaciones de $\mathrm{I}+\mathrm{D}+\mathbf{i}$ y la llamada 'contabilidad verde'}

La introducción de incentivos fiscales a la $\mathrm{I}+\mathrm{D}+\mathrm{i}$ debe ir acompañada de un riguroso sistema de certificaciones. De esta forma, las entidades que están llevando a cabo un proceso de $\mathrm{I}+\mathrm{D}+\mathrm{i}$ obtienen ciertas certificaciones o declaraciones de $\mathrm{I}+\mathrm{D}+\mathrm{i}$ por los entes, organismos y agencias estatales competentes en investigación, facilitando, así, la posterior aplicación del incentivo fiscal. No puede decirse que una medida fiscal dirigida a la promoción de la $\mathrm{I}+\mathrm{D}+\mathrm{i}$ esté efectivamente fomentando este tipo de actividades si la misma no es conocida por el contribuyente en el momento en que decide llevar a cabo un proceso de I+D+i. En muchos casos, la falta de información es la que dificulta a las empresas el acceso a los incentivos fiscales a la $\mathrm{I}+\mathrm{D}+\mathrm{i}$, así como el desconocimiento sobre la calificación que va a tener el proyecto (por ejemplo, si se trata de investigación o de desarrollo experimental $)^{43}$.

En relación con esto último, las empresas, en muchas ocasiones, se mueven en un área de inseguridad jurídica acerca de si las actividades que están realizando son, en efecto, de $\mathrm{I}+\mathrm{D}+\mathrm{i}$, es decir, si encajan o no en el concepto de $\mathrm{I}+\mathrm{D}+\mathrm{i}$ que a efectos fiscales se establece ${ }^{44}$. Por tanto, la obtención de una certificación de que la actividad que se está llevando a cabo es, por ejemplo, de innovación tecnológica, permite que el contribuyente tenga la certeza respecto de la aplicación del incentivo; y, al mismo tiempo vendría a suplir los posibles 'aspectos grises' de la definición de $\mathrm{I}+\mathrm{D}+\mathrm{i}$. En otras palabras, permite al contribuyente conocer la elegibilidad del proyecto o la actividad llevada a cabo.

A este respecto, AFIDI señala que la certificación de las actividades requiere unos costes y un tiempo considerables que pueden constituir un desincentivo especialmente para las pymes ${ }^{45}$. Ello requiere, pues, que la obtención de las certificaciones se caracterice por la agilidad y simplificación del procedimiento.

${ }^{43}$ En un estudio de 2019 preparado para la DG Competencia, las entidades encuestadas señalaron que el tipo de proyectos que llevaron a cabo en el período 2015-2017 fueron principalmente de desarrollo experimental y de agrupaciones de innovación ('innovation clusters') (COMISIÓN EUROPEA y ECORYS (2019), Study on the practical impact of RDI State aid rules, Publications Office of the European Union, p. 70).

${ }^{44}$ Consideramos que no debe haber distinción entre la definición de $\mathrm{I}+\mathrm{D}+\mathrm{i}$ dada por la comunidad científica y el concepto a efectos tributarios (E. Gil García, Los incentivos..., p. 75).

${ }^{45}$ AFIDI (2020), op. cit. 
La evaluación de la idoneidad del proyecto o actividad ha de realizarla un experto o técnico en la materia; pues, como ha advertido senda jurisprudencia española ${ }^{46}$, los aspectos técnicos y científicos de los proyectos de $\mathrm{I}+\mathrm{D}+\mathrm{i}$ así lo requieren. Ese es, por ejemplo, el caso de Austria donde la evaluación sobre la idoneidad del proyecto la realiza un experto o técnico en la materia, mediante la Agencia de Promoción de la Investigación.

Resulta positivo que esas certificaciones sean vinculantes para la Administración tributaria (extremo observado en diferentes jurisdicciones de nuestro entorno). Incluso, puede destacarse positivamente que esa obligatoriedad lo sea también para el contribuyente (por ejemplo, Austria y Holanda); pues, sería una forma de disminuir, en gran medida, esa sensación de inseguridad jurídica frente a una posible inspección tributaria. Ahora bien, la obtención de una certificación como exigencia o requisito previo ha de ir acompañada de agilidad en el proceso de concesión, siendo una posible solución tomar en consideración las certificaciones realizadas por las universidades u OPIs.

Podría considerarse también que hubiese un control a posteriori (como ocurre en Holanda) respecto de las actividades de I+D+i llevadas a cabo y favorecidas fiscalmente. De esta forma, podrían evitarse arbitrariedades en la concesión de incentivos fiscales ( $\mathrm{y}$ asegurar que únicamente las auténticas actividades de I+D+i están recibiendo ese tratamiento fiscal preferente). Ahora bien, la carga que para el contribuyente puede suponer esas evaluaciones (tanto ex ante como a posteriori) debería compensarse con procedimientos ágiles (como ya se ha dicho), así como con extensa información, e incluso manuales o guías, sobre los requisitos y el proceso de solicitud de la certificación.

Esas certificaciones de $\mathrm{I}+\mathrm{D}+\mathrm{i}$ no solamente confieren seguridad jurídica a las entidades respecto de la aplicación del incentivo, sino que son también una forma de mejorar el control respecto de la concesión de incentivos fiscales, haciendo pues que el gasto público destinado a $\mathrm{I}+\mathrm{D}+\mathrm{i}$ sea más eficiente. Esto es, permiten verificar que solamente las entidades que están llevando a cabo actividades de $\mathrm{I}+\mathrm{D}+\mathrm{i}$ (certificadas como tal) se benefician del incentivo fiscal.

También contribuye al control, la llamada 'contabilidad verde' ${ }^{\text {'7 }}$, a través de la cual la empresa refleja el impacto ambiental de sus acciones o actividades (por ejemplo, el uso de recursos). Permite, pues, determinar el grado de implementación de la eco-innovación en las actividades de la empresa y, por tanto, el adecuado uso de la

${ }^{46}$ Entre otras, la sentencia del Tribunal Supremo de 12 de enero de 2014 y las sentencias de la Audiencia Nacional de 20 de junio de 2013, de 30 de mayo de 2011 y de 9 de diciembre de 2010.

${ }^{47} \mathrm{La}$ contabilidad verde (o contabilidad ambiental) es una parte esencial de la responsabilidad social corporativa que va a ayudar en la toma de decisiones de inversión de una empresa al comparar los costes de evitar o prevenir un daño ambiental con el coste de repararlo (Plan de Acción sobre Eco-innovación, UE: https://ec.europa.eu/environment/ecoap/about-eco-innovation/policies-matters/eu/703_es [acceso 13 marzo 2021]). 
ayuda fiscal al desarrollo de alternativas más innovadoras. Dado que la eco-innovación contribuye a un consumo de recursos y producción de bienes o servicios más sostenible $^{48}$, la contabilidad ambiental, al reflejar los costes asociados al impacto de la actividad en el medio ambiente, ayudaría a una asignación más eficaz de recursos escasos. Es decir, a la toma de decisiones de las empresas respecto de las distintas fases de un bien o servicio, desde la extracción de materias primas pasando por su fabricación y distribución hasta su eliminación o reutilización. En relación con la sostenibilidad en todas las fases del ciclo de vida de un determinado producto, cabe destacar que el Plan de Acción de la UE para la economía circular establece, entre otras medidas, la financiación e incentivos económicos para estimular métodos de producción y consumo más innovadores ${ }^{49}$. Por tanto, la introducción de esos incentivos o medidas de estímulo deberán ir acompañadas de un control, requiriendo los correspondientes avances en la contabilidad verde que permitan llevar a cabo el citado control.

\section{Conclusiones}

En este trabajo se ha puesto de manifiesto la importancia de fortalecer las economías de los Estados miembros y aumentar su resiliencia a partir del desarrollo de modelos empresariales más sostenibles, basados en la eco-innovación. Especial atención debe prestarse a las pymes, dado que el tejido empresarial de la UE está principalmente compuesto por ellas, teniendo normalmente mayores dificultades para iniciar y llevar a cabo su actividad en un mercado único, pero reportando, al mismo tiempo, mayores ventajas la implantación de la eco-innovación por su parte. Ahora bien, la conversión o transformación en pymes eco-innovadoras va a precisar de apoyo a la $\mathrm{I}+\mathrm{D}+\mathrm{i}$ de modo que se pueda acelerar la adopción de soluciones y alternativas más innovadoras y eficientes respecto de los procesos productivos y de todas las actividades de la empresa.

Así pues, el apoyo público a la $\mathrm{I}+\mathrm{D}+\mathrm{i}$ se erige como uno de los pilares en torno a los cuales giraría una política de estímulos a la eco-innovación, siendo los incentivos fiscales a la $\mathrm{I}+\mathrm{D}+\mathrm{i}$ uno de los instrumentos.

Para conseguir efectivamente el objetivo de aumentar la inversión empresarial en $\mathrm{I}+\mathrm{D}+\mathrm{i}$ y que, por tanto, las empresas, especialmente las pymes, puedan ser innovadoras, es esencial determinar cómo se van a diseñar los incentivos fiscales, y el control que sobre su concesión se va a efectuar.

El presente trabajo nos permite concluir, en primer lugar, que el incentivo fiscal ha de configurarse como una deducción en cuota basada en un sistema mixto. Esto es, que se tenga en cuenta tanto el volumen de gastos en $\mathrm{I}+\mathrm{D}+\mathrm{i}$ efectuados en un

\footnotetext{
${ }^{48}$ ONU Medio Ambiente (con la Comisión Europea), Integración..., pp. 17 y 26.

${ }^{49}$ Véase $\operatorname{COM}(2019) 190$ final, Informe sobre la aplicación del Plan de acción para la economía circular.
} 
determinado ejercicio económico como el incremento de gastos con respecto a los años anteriores (es decir, la realización de $\mathrm{I}+\mathrm{D}+\mathrm{i}$ adicional). Por el contrario, la configuración del incentivo fiscal como una deducción en cuota sobre el incremento podría actuar como un desincentivo para las pymes al tener una menor capacidad para aumentar paulatinamente su inversión en $\mathrm{I}+\mathrm{D}+\mathrm{i}$.

Segundo, especial consideración ha de hacerse respecto a que el incentivo estimule tanto la contratación de personal investigador cualificado que coadyuve a que las pymes puedan llevar a cabo su propio proceso de $\mathrm{I}+\mathrm{D}+\mathrm{i}$ (siendo ello, como veíamos, un indicador de eco-innovación), como el fomento de la transferencia de conocimiento. De hecho, la falta de interacción entre el sector empresarial y el sector público de investigación es una de las barreras para la eco-innovación, pero también uno de los aspectos que caracterizan la falta de inversión empresarial en $\mathrm{I}+\mathrm{D}+\mathrm{i}$. La promoción desde el sistema tributario de la transferencia de conocimiento (por ejemplo, mediante deducciones adicionales) entre los diferentes agentes que realizan $\mathrm{I}+\mathrm{D}+\mathrm{i}$ va a implicar el intercambio de experiencias y la difusión de alternativas más innovadoras y eficientes que permitan alcanzar los retos ambientales.

Finalmente, deviene imprescindible que la concesión de incentivos fiscales no adolezca de arbitrariedad ni los mismos resulten ineficaces, por lo que además de un diseño en línea con los principios de justifica tributaria, va a ser necesario efectuar un control que asegure la eficiencia en la utilización del gasto público. A este respecto, el trabajo se ha centrado en el establecimiento de un riguroso sistema de certificaciones de $\mathrm{I}+\mathrm{D}+\mathrm{i}$ que pasa porque los proyectos $\mathrm{y}$ actividades de $\mathrm{I}+\mathrm{D}+\mathrm{i}$ sean evaluados por expertos ( $\mathrm{y}$ no por el personal de las Administraciones tributarias que carecen de conocimientos técnicos), y que la obtención de aquellas se enmarque en un procedimiento caracterizado por su agilidad y simplificación. Ello además redundará en la seguridad jurídica.

Junto a esto, se ha hecho también una breve referencia a la denominada 'contabilidad verde' (o 'contabilidad ambiental') que permitiría controlar la implantación de la eco-innovación por parte de las empresas, pero que requerirá de avances y una regulación clara para que la misma puede ser integrada en la 'tradicional' contabilidad económica de las empresas.

\section{Streszczenie / Resumen extenso}

\section{Ekoinnowacje, MŚP i zachęty podatkowe}

Celem niniejszego opracowania było uwypuklenie konieczności wzmocnienia gospodarek państw członkowskich Unii Europejskiej i zwiększenia ich odporności poprzez opracowanie bardziej zrównoważonych modeli biznesowych opartych na ekoinnowacjach. Szczególną uwagę należy zwrócić na małe i średnie przedsiębior- 
stwa (MŚP), zważywszy, że struktura przedsiębiorstw UE składa się głównie z MŚP, które zwykle mają pewne trudności z rozpoczęciem i prowadzeniem działalności na jednolitym rynku, ale jednocześnie wdrożenie ekoinnowacji z ich strony przynosi duże korzyści. Przekształcenie lub zmiana w ekoinnowacyjne MŚP wymaga jednak wsparcia dla $\mathrm{B}+\mathrm{R}+\mathrm{I}^{50} \mathrm{~W}$ celu przyspieszenia przyjęcia bardziej innowacyjnych i wydajnych rozwiązań i alternatyw w odniesieniu do procesów produkcyjnych i całej działalności przedsiębiorstwa. Należy również pamiętać, że dojrzałość tak zwanych zielonych technologii nie zawsze jest na wystarczająco zaawansowanym etapie, aby sprostać wyzwaniom środowiskowym.

Dlatego też publiczne wsparcie dla B+R+I jest jednym z filarów, wokół którego powinna się koncentrować polityka stymulująca ekoinnowacje, a jednym $z$ instrumentów być zachęty podatkowe dla B+R+I. Należy zauważyć, że wsparcie publiczne na rzecz $\mathrm{B}+\mathrm{R}+\mathrm{I}$ jest uzasadnione tym, że ma ono kluczowe znaczenie dla wzrostu gospodarczego kraju, zrównoważonego rozwoju i dobrobytu społecznego, co zazwyczaj wynika z konstytucji (jak w wypadku Hiszpanii, Włoch i Portugalii) lub jest częścią polityki państw w zakresie interesu publicznego.

Chociaż istnieją liczne instrumenty na rzecz rozwoju, które mogą być wykorzystywane do finansowania $\mathrm{B}+\mathrm{R}+\mathrm{I}$ (takie jak dotacje czy pożyczki udzielone przez wspólnika), w niniejszym opracowaniu skupiono się na wykorzystaniu zachęt podatkowych (lub - jak nazywają je ekonomiści - „kosztów podatkowych”). Zachęty podatkowe na rzecz $\mathrm{B}+\mathrm{R}+\mathrm{I}$ mogą być uzależnione od działalności (input incentives) lub od wyników, np. system patent box. W niniejszym opracowaniu skoncentrowano się na pierwszym z nich, a w szczególności na konfiguracji kwot do odliczenia, ponieważ jest to najbardziej rozpowszechniona forma w państwach członkowskich UE.

Żeby skutecznie osiągnąć cel polegający na zwiększeniu inwestycji przedsiębiorstw w B+R+I, a tym samym innowacyjności przedsiębiorstw, zwłaszcza MŚP, istotne jest, $\mathrm{w}$ jaki sposób zostaną opracowane zachęty podatkowe i jaka będzie kontrola nad ich przyznawaniem.

Mając to na uwadze, przeanalizowano, czy kwota odliczenia powinna być ustalana na podstawie wielkości czy wzrostu nakładów na $\mathrm{B}+\mathrm{R}+\mathrm{I}$. Podczas gdy pierwsza z nich jest oparta na wartości procentowej stosowanej do całkowitych kosztów poniesionych w roku podatkowym, druga jest stosowana w wypadku wzrostu kosztów $\mathrm{B}+\mathrm{R}+\mathrm{I}$ w stosunku do roku poprzedniego lub średniej z ostatnich lat. Obie opcje mają zarówno zalety, jak i wady. Na przykład kwota odliczenia ustalana na postawie wzrostu pobudziłaby realizację dodatkowych nakładów na $\mathrm{B}+\mathrm{R}+\mathrm{I}$, ale mogłaby doprowadzić do tego, że niektóre przedsiębiorstwa zdecydowałyby się ograniczyć swoją działalność $\mathrm{B}+\mathrm{R}+\mathrm{I}$, aby w przyszłości skorzystać z tej zachęty (co nie byłoby pożądanym celem, gdyż, jak wspomniano powyżej, jest nim zwiększenie inwestycji przedsiębiorstw w zakresie $\mathrm{B}+\mathrm{R}+\mathrm{I})$. W związku $\mathrm{z}$ tym uznano, że zachęta podat-

\footnotetext{
${ }^{50}$ Sektor badań, rozwoju i innowacji.
} 
kowa powinna zostać skonfigurowana jako kwota odliczenia oparta na systemie mieszanym. W ten sposób zostanie uwzględniona zarówno wielkość nakładów na $\mathrm{B}+\mathrm{R}+\mathrm{I}$ poniesionych $\mathrm{w}$ danym roku obrachunkowym, jak i wzrost kosztów w stosunku do lat poprzednich. $Z$ drugiej strony konfiguracja zachęty podatkowej jako kwoty odliczenia od wzrostu mogłaby działać zniechęcająco na MŚP, ponieważ miałyby one mniejsze możliwości stopniowego zwiększania swoich inwestycji w zakresie B + R+I. W przypadku Hiszpanii odliczenie, o którym mowa w art. 35 LIS [Ley del impuesto sobre sociedades - Ustawa o podatku dochodowym od osób prawnych], jest konfigurowane na zasadach systemu mieszanego, określającego stałą stawkę procentową w wysokości $25 \%$ wydatków na $\mathrm{B}+\mathrm{R}$ w danym roku obrachunkowym oraz dodatkową stawkę procentową w wysokości $42 \%$ w wypadku wzrostu.

Oprócz formy, jaką przybiera zachęta, istnieje kilka kwestii lub aspektów, które należy uwzględnić przy jej konfigurowaniu lub projektowaniu. Biorąc pod uwagę, że nabycie środków trwałych i zatrudnienie wysoko wykwalifikowanego personelu badawczego jest zwykle najdroższą częścią procesu $\mathrm{B}+\mathrm{R}+\mathrm{I}$, ale jednocześnie zasadniczą częścią każdego procesu B+R+I, podstawa zachęty powinna pokrywać te koszty. Ponadto należy zauważyć, że personel $\mathrm{B}+\mathrm{R}$ i naukowcy są jednym ze wskaźników ekoinnowacji uwzględnionych w Planie działania UE w zakresie ekoinnowacji. W wypadku Hiszpanii w art. 35 LIS odliczenie na działalność $B+R$ obejmuje dodatkowe odliczenie w wysokości 17\% kwoty kosztów personelu. Uważamy tę opcję za pozytywną, ponieważ oprócz stymulowania zatrudnienia personelu badawczego poprzez możliwość odliczania kosztów działalności badawczo-rozwojowej może pomóc MŚP w prowadzeniu procesów $B+R+I$ samodzielnie, gdyż aby skorzystać $z$ odliczenia, konieczne jest, by personel badawczy był przydzielony wyłącznie do działalności B+R .

W niniejszym opracowaniu podkreślono również związek między odliczeniem podatku a bonifikatami w zakresie składki na ubezpieczenie społeczne w odniesieniu do kadry badawczej dla MŚP, które uzyskują status innowatorów. W ten sposób zachęta dla MŚP do zatrudniania badaczy w celu prowadzenia działalności $\mathrm{B}+\mathrm{R}+\mathrm{I}$ jest większa. W związku $\mathrm{z}$ tym MŚP będą miały status innowatora $\mathrm{w}$ trzech sytuacjach - jeśli uzyskają finansowanie $\mathrm{w}$ przetargach publicznych $\mathrm{B}+\mathrm{R}+\mathrm{I}$, jeśli będą mieć własny patent lub jeśli uzyskają określone certyfikaty (np. innowacyjnej mikrofirmy).

W odniesieniu do idei innowacyjnych MŚP istnieje kilka badań, w których okazało się, że zachęty podatkowe skierowane do takich firm są zazwyczaj bardzo skuteczne. Z kolei Komisja Europejska w badaniu z 2014 roku wskazała, że tworzenie korzystnego klimatu dla przedsiębiorców i młodych przedsiębiorstw (takich jak start-upy) przyczynia się do innowacyjności i elastyczności gospodarczej kraju. W rzeczywistości za dobrą praktykę podatkową uznano w tym badaniu francuski system „Jeune Entreprise Innovante”, który miał na celu zachęcanie do tworzenia innowacyjnych MŚP poprzez przyznawanie ulg podatkowych i bonifikat w zakresie składek na ubezpieczenie społeczne. 
Jak wskazano w tym rozdziale, to, że zachęta podatkowa w dużym stopniu sprzyja niektórym podmiotom takim jak MŚP, może być sprzeczne z zakazem pomocy państwa zawartym $\mathrm{w}$ art. 107 TFUE. Jednak pomimo wyboru per se tej zachęty można przyjąć, że odpowiada ona uzasadnieniu, co oznaczałoby zgodność środka $\mathrm{z}$ prawem UE.

$\mathrm{Z}$ innej strony należy zwrócić szczególną uwagę na wsparcie transferu wiedzy. $\mathrm{W}$ rzeczywistości brak interakcji między sektorem biznesowym a publicznym sektorem badawczym jest jedną z barier dla ekoinnowacji (jak wskazała ONZ w swoim raporcie na temat ekoinnowacji w 2017 roku), a także jednym $\mathrm{z}$ aspektów charakteryzujących brak inwestycji biznesowych w B+R+I (jak wskazało Hiszpańskie Stowarzyszenie na rzecz Wsparcia Finansowania B+R+I). Promowanie przez system podatkowy transferu wiedzy między różnymi podmiotami prowadzącymi działalność $\mathrm{B}+\mathrm{R}+\mathrm{I}$ będzie oznaczało wymianę doświadczeń i rozpowszechnianie bardziej innowacyjnych i wydajnych alternatyw, które pozwolą sprostać wyzwaniom związanym $\mathrm{z}$ ochroną środowiska. W ten sposób przedsiębiorstwa, które nie mają własnego działu $\mathrm{B}+\mathrm{R}+\mathrm{I}$ lub nie mają możliwości samodzielnego prowadzenia procesu $\mathrm{B}+\mathrm{R}+\mathrm{I}$ (jak jest zazwyczaj w wypadku MŚP), korzystają $\mathrm{z}$ laboratoriów, urządzeń i personelu uniwersytetów lub publicznych instytucji badawczych (PRI).

Dlatego celem podejmowanych działań jest zachęcanie do tworzenia pomostów między publicznym sektorem badawczym a sektorem przedsiębiorstw poprzez ustanowienie na przykład wyższego odliczenia w takich wypadkach. W Hiszpanii przewidziano bowiem dodatkowe odliczenie w wysokości $20 \%$ wydatków na projekty $\mathrm{B}+\mathrm{R}$ zlecane uniwersytetom, PRI lub ośrodkom innowacji i technologii, uznanym i zarejestrowanym zgodnie z przepisami hiszpańskimi. W praktyce oznaczało to, że hiszpańskie firmy powierzyły zadania $\mathrm{B}+\mathrm{R}$ uczelniom lub instytucjom badawczym znajdującym się na terytorium Hiszpanii, bo choć ośrodek badawczy nie musiał znajdować się w Hiszpanii, to konieczne było prowadzenie działalności w Hiszpanii w celu uzyskania wyżej wskazanego odliczenia (w wysokości 20\%). Mając powyższe na uwadze, w wyroku z marca 2008 roku TSUE orzekł, że to dodatkowe odliczenie narusza podstawowe wolności, co spowodowało, że zamiast rozszerzać je w przypadku podzlecania $\mathrm{B}+\mathrm{R}$ uczelniom lub ośrodkom badawczym zlokalizowanym nie tylko w Hiszpanii, ale także w innych krajach UE / państwach członkowskich EOG, rząd hiszpański zdecydował się je zlikwidować.

Należy jednak pamiętać, że cel, którym jest promowanie ogólnokrajowych $\mathrm{B}+\mathrm{R}+\mathrm{I}$, nie może oznaczać ograniczenia podstawowych wolności oraz że art. 179 TFUE opowiada się właśnie za utworzeniem europejskiej przestrzeni badawczej.

Ponadto istotne jest, aby przyznawanie zachęt podatkowych nie było arbitralne lub nieskuteczne, tak więc oprócz projektu zgodnego z zasadami uzasadnienia podatkowego konieczne będzie przeprowadzenie kontroli zapewniającej efektywność wykorzystania wydatków publicznych. W tym zakresie prace koncentrowały się na ustanowieniu rygorystycznego systemu certyfikacji B+R+I. Oznacza to, że projekty 
i działania $\mathrm{B}+\mathrm{R}+\mathrm{I}$ powinny być oceniane przez ekspertów (a nie przez pracowników administracji podatkowej, którzy nie mają wiedzy technicznej). Ponadto procedura uzyskiwania certyfikacji $\mathrm{B}+\mathrm{R}+\mathrm{I}$ powinna się charakteryzować sprawnością i uproszczeniem, zwłaszcza jeśli, jak podkreślono w tym rozdziale, uzyskanie certyfikacji jest ustanowione jako wymóg korzystania z zachęty podatkowej.

Poza możliwością kontroli nad przyznawaniem zachęt podatkowych uzyskanie certyfikatu $\mathrm{B}+\mathrm{R}+\mathrm{I}$ zwiększa również pewność prawną. Oznacza to, że podmiot, który uzyska certyfikat dla prowadzonych przez siebie działań lub projektów, ma pewność co do zastosowania zachęty.

W opracowaniu krótko odniesiono się także do kwestii „zielonej rachunkowości” (lub „rachunkowości środowiskowej”), która umożliwiłaby kontrolę wdrażania ekoinnowacji przez przedsiębiorstwa. Będzie ona jednak wymagała postępu i jasnych regulacji, aby można ją było włączyć do „tradycyjnej” rachunkowości gospodarczej przedsiębiorstw.

\section{Bibliografía}

Abdellatif M., Looking for Efficient Tax Incentives to Stimulate Research and Development and Economic Growth, „New Zealand Journal of Taxation and Policy” 2009, vol. 15, n 2.

AFIDI (2020), Dura crítica de Bruselas a los incentivos fiscales a la I+D en España: son complejos e ineficaces (disponible en el sitio web de AFIDI: http://www.afidi.es/2020/04/06/dura-critica-de-bruselas-a-los-incentivos-fiscales-a-la-id-en-espana-son-complejos-e-ineficaces/ [acceso 13 marzo 2021]).

Alonso Murillo F., Fiscalidad de la I+D+i. Tratamiento de los gastos en el Impuesto sobre Sociedades, Netbiblo, 2010.

Arginelli P., Innovation through R\&D Tax Incentives: Some Ideas for a Fair and Transparent Tax Policy, „World Tax Journal” 2015, vol. 7, n 1 .

Baghana, R., Mohnen, P., Effectiveness of $R \& D$ tax incentives in small and large enterprises in Quebec, „Small Business Economics” 2009, vol. 33, nº 1.

Bal A., Competition for Research \& Development Tax Incentives in the European Union - How and Optimal Research \& Development System Should Be Designed, „Bulletin for International Taxation” 2012, vol. 66, n 10 .

Bal A., Tax Incentives: III-Advised Tax Policy or Growth Catalaysts?, „European Taxation” 2014, vol. 54, $n^{\circ} 2 / 3$.

Brokelind C., Hansson A., Tax Incentives, Tax Expenditures Theories in R\&D: The Case of Sweden, „World Tax Journal” 2014, vol. 6, nº 2 .

COM (2020) 575 final, Estrategia anual de crecimiento sostenible 2021.

COM(2019) 190 final, Informe sobre la aplicación del Plan de acción para la economía circular.

Comisión Europea (2020), Informe sobre España que acompaña a la Comunicación sobre el Semestre Europeo 2020, COM(2020) 150 final.

Comision Europea y Ecorys (2019), Study on the practical impact of RDI State aid rules, Publications Office of the European Union.

Comisión Europea, A Study on R\&D Tax Incentives. Final report, Working Paper nº 52, 2014.

Corchuelo Martínez-Azúa, B., Incentivos fiscales a la I+D en la OCDE: estudio comparativo, „Cuadernos económicos de ICE” 2007, n 73. 
FMI (2020), Temporary Investment Incentives, Fiscal Affairs - Special Series on COVID-19.

Gil García E., A review of the pre and post COVID-19 State aid rules in the area of R\&D\&I, „Crónica Tributaria" 2020, nº 175.

Gil García E., Los incentivos fiscales a la $I+D+i$, Tirant lo Blanch, 2017.

Lokshin, B., Mohnen, P., Measuring the Effectiveness of R\&D tax credits in the Netherlands, CIRANO-Scientific Publications, 2007.

Milne, J.E., Villar, M., Renewable Electricity and Tax Expenditures: Lessons from Two Countries, „Intertax" 2020, vol. $48, \mathrm{n}^{\circ} 4$.

OECD (2020), Tax and Fiscal Policy in Response to the Coronavirus Crisis: Strengthening Confidence and Resilience, OECD Publishing.

ONU Medio Ambiente (con la Comisión Europea), Integración de la eco-innovación en las Políticas de consumo y producción sostenibles, 2017.

Pérez Bernabeu, B., La I+D+i colaborativa a la luz de la normativa sobre ayudas de Estado (Especial referencia a las Spin-off universitarias), „Crónica Tributaria” 2015, nº 156.

Rivas Sánchez, C., Los incentivos fiscales a la innovación en España y en el ámbito comparado, „Crónica Tributaria" 2008, n 127. 